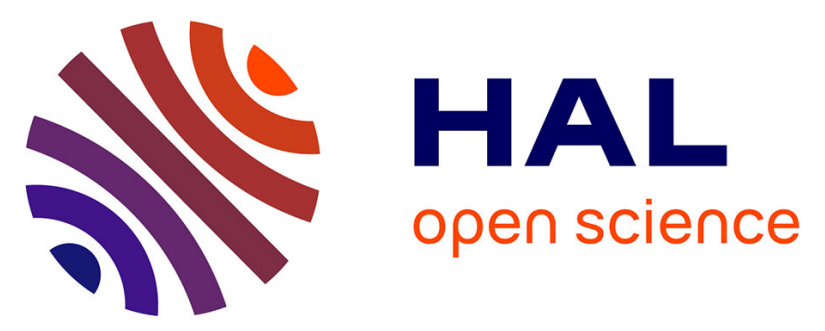

\title{
Large-Signal Stable Nonlinear Control of DC/DC Power Converter with Online Estimation of Uncertainties
}

\author{
Shengzhao Pang, Babak Nahid-Mobarakeh, Serge Pierfederici, Yigeng
}

Huangfu, Guangzhao Luo, Fei Gao

\section{- To cite this version:}

Shengzhao Pang, Babak Nahid-Mobarakeh, Serge Pierfederici, Yigeng Huangfu, Guangzhao Luo, et al.. Large-Signal Stable Nonlinear Control of DC/DC Power Converter with Online Estimation of Uncertainties. IEEE Journal of Emerging and Selected Topics in Power Electronics, 2020, 10.1109/JESTPE.2020.3010895 . hal-03192926

\section{HAL Id: hal-03192926 \\ https://hal.univ-lorraine.fr/hal-03192926}

Submitted on 10 May 2021

HAL is a multi-disciplinary open access archive for the deposit and dissemination of scientific research documents, whether they are published or not. The documents may come from teaching and research institutions in France or abroad, or from public or private research centers.
L'archive ouverte pluridisciplinaire HAL, est destinée au dépôt et à la diffusion de documents scientifiques de niveau recherche, publiés ou non, émanant des établissements d'enseignement et de recherche français ou étrangers, des laboratoires publics ou privés.

\section{(c)(1)}

Distributed under a Creative Commons Attribution| 4.0 International License 


\title{
Large-Signal Stable Nonlinear Control of DC/DC Power Converter with Online Estimation of Uncertainties
}

\author{
Shengzhao Pang, Student Member, IEEE, Babak Nahid-Mobarakeh, Senior Member, IEEE, \\ Serge Pierfederici, Yigeng Huangfu, Senior Member, IEEE, Guangzhao Luo, Member, IEEE, \\ and Fei Gao, Senior Member, IEEE
}

\begin{abstract}
The Passivity-Based Control (PBC) is recognized as an effective energy shaping approach to guarantee the asymptotic stability of the whole system by using the passivity property. However, the model-based and sensor-based characteristics limit its development and application. The combination of the PBC and online estimation technique can solve these problems. The purpose of this paper is to propose a controller and an observer, which are designed simultaneously based on Hamiltonian framework and Lyapunov criterion. It leads to the system design without separation of the dynamics of the controller and the observer. The uncertainties in the model and parameters are considered as equivalent voltage and current sources. To reduce the number of sensors, input voltage, output current, and equivalent sources are estimated together. The steady-state error is eliminated by using this estimation technique. The exponential stability of the whole system (converter, controller, and observer) is proved by using a proper Lyapunov function. Simulation and experimental results from a $3 \mathrm{~kW} \mathrm{270-350} \mathrm{V} \mathrm{DC/DC} \mathrm{boost} \mathrm{converter} \mathrm{with} \mathrm{a} \mathrm{Constant}$ Power Load (CPL) are performed to confirm the proposed control algorithm. Since the system parameter values may vary with temperature and the equilibrium point, the robustness of the proposed method is verified without and with parameters uncertainties.
\end{abstract}

Index Terms-Large-signal stability, Interconnection and damping assignment passivity-based control (IDA-PBC), portcontrolled Hamiltonian (PCH), microgrid, DC/DC converter, constant power load (CPL), online estimation.

\section{NOMENCLATURE}

RESs

MEA

$\mathrm{EV} / \mathrm{HEV} \mathrm{s}$

Renewable Energy Sources.

More Electric Aircraft.

Electric Vehicles/Hybrid Electric Vehicles.
S. Pang is with the Groupe de Recherche en Energie Electrique de Nancy, and the Laboratoire d'Energétique et de Mécanique Théorique et Appliquée, École Nationale Supérieure d'Électricité et de Mécanique, Université de Lorraine, Nancy 54500, France (e-mail: shengzhao.pang@univ-lorraine.fr).

B. Nahid-Mobarakeh is with the Groupe de Recherche en Energie Electrique de Nancy, École Nationale Supérieure d'Électricité et de Mécanique, Université de Lorraine, Nancy 54500, France (e-mail: babak.nahidmobarakeh@univlorraine.fr)
PBC Passivity-Based Control.

IDA-PBC Interconnection and Damping Assignment Passivity-Based Control.

PCH Port-Controlled Hamiltonian.

CPL Constant Power Load.

$H(x) \quad$ Hamiltonian function.

$H_{d}(x) \quad$ Closed-loop Hamiltonian function.

$J \quad$ Interconnection matrix.

$J_{d} \quad$ Desired interconnection matrix.

$R, R_{d} \quad$ Dissipation matrix and damping matrix.

$K(x) \quad$ Adaptive variable in the matrix $J_{d}$.

$\alpha, u, d \quad$ Switch command, control input of the system, and duty cycle.

$\gamma_{v}, \gamma_{i} \quad$ Equivalent voltage and current sources $V_{e}, i_{c h}$ (internal disturbance/uncertainties).

DC-bus input voltage and output current (external disturbance).

Disturbance, i.e. $\rho_{v}=V_{e}-\gamma_{v}$ and $\rho_{i}=i_{c h}+\gamma_{i}$.

Boost converter inductor current.

$i_{L}$

$v_{o}$

$i_{d}$

$V_{d}\left(V_{\text {ref }}\right)$

$x$

$x_{d}$

Boost converter capacitor voltage.

Desired value of inductor current.

Desired value of capacitor voltage.

State variable, i.e. $x=\left[\begin{array}{ll}x_{1} & x_{2}\end{array}\right]^{T}=\left[\begin{array}{ll}i_{L} & v_{0}\end{array}\right]^{T}$. Desired equilibrium point of $x$, i.e. $x_{d}=\left[\begin{array}{ll}x_{1 d} & x_{2 d}\end{array}\right]^{T}=\left[i_{d} V_{d}\right]^{T}$.

Estimation value of $x$ i.e. $\hat{x}=\left[\hat{x}_{1} \hat{x}_{2}\right]^{T}=\left[\hat{l}_{L} \hat{v}_{o}\right]^{T}$.

$\hat{\rho} \quad$ Estimation value of the unknown parameter $\rho$, i.e. $\hat{\rho}=\left[\hat{\rho}_{v} \hat{\rho}_{i}\right]^{T}$.

$k_{s}, k_{i}, k_{p} \quad$ Coefficient matrices (diagonal) in the observer.
S. Pierfederici is with the Laboratoire d'Energétique et de Mécanique Théorique et Appliquée, École Nationale Supérieure d'Électricité et de Mécanique, Université de Lorraine, Nancy 54500, France (e-mail: serge.pierfederici@univ-lorraine.fr).

Y. Huangfu and G. Luo are with the School of Automation, Northwestern Polytechnical University, Xi'an 710072, China (e-mail: yigeng@nwpu.edu.cn; guangzhao.luo@nwpu.edu.cn).

F. Gao is with the FEMTO-ST Institute and the FCLAB, Universite Bourgogne Franche-Comté, UTBM, Belfort 90010, France (e-mail: fei.gao@utbm.fr). 


\section{INTRODUCTION}

Over the past decades, the revolution in the energy system is moving towards low-carbon, green and sustainable development, especially in the field of electrified transportation, such as More Electric Aircraft (MEA), Electric Vehicles /Hybrid Electric Vehicles (EVs/HEVs), ships, and submarines [1], [2], [3]. In these applications, Renewable Energy Sources (RESs) such as Photovoltaics (PV) and Fuel Cells (FCs) are integrated into the power distribution system, which can reduce greenhouse gas emissions and provide clean energy for sustainable development [4], [5]. However, this poses an increasing challenge to the design of the on-board electrical system. The whole system stabilization, consumption optimization, and advanced control exploitation are mainly concerned in such applications [6], [7].

Considering that the electrified transportation system is an isolated energy distribution system, this system can be considered as an on-board microgrid [8], [9]. To regulate the energy flow and adapt the voltage relationship among multiple RESs and loads, power electronic converters especially DC/DC power converters are employed [10]. Therefore, it is of significant importance to explore the control strategy with attractive properties of static and dynamic performances. The key points of the Control Objectives are:

1) The high robustness properties and good dynamic responses are particularly important for the power conversion system, which play an essential role in obtaining satisfying performance.

2) The stability of each DC/DC converter has to be ensured, and then the whole system stability of the on-board microgrid should be verified.

3) The regulation accuracy of the state variable is an important factor for controller design. The objective of the controller is to achieve zero steady-state error.

4) To increase power density and reduce energy consumption, one way is to reduce the number of sensors.

As for the Objective 1), quite a few nonlinear control methods have been proposed to improve the transient performance and robustness of the DC/DC power converters, including flatness-based control [11], sliding-mode control [12], Lyapunov-based control [13], model predictive control [14] or passivity-based control [15]. All these typical well-developed control methods can achieve fast dynamic responses and high robustness properties.

However, even though each subsystem in the microgrid can work well individually, the whole system might suffer from instability issues due to their interactions [16]. Thus, the control method should not only ensure the stability of the individual converter, but also ensure the stability of the entire system as stated in Objective 2). The Passivity-Based Control (PBC) is attractive for solving this problem due to the passivity property. $\mathrm{PBC}$ is a generic name, to define the energy shaping control methodology that stabilizes the system by rendering it passive
[17], [18]. The significant trait of the passivity criterion is that the passivity is preserved in arbitrary interconnections [19]. If a group of passive-ensured subsystems is connected by parallel or feedback, the entire system is passive and thereby stable [20]. The intuitive reason is that the energy supplied to the combined system is dissipated by the subsystems separately. This conclusion can be further generalized to an arbitrary number of interconnected subsystems, by applying the passivity principle iteratively [21], [22].

The Interconnection and Damping Assignment PassivityBased Control (IDA-PBC) is introduced by [17] as a branch of $\mathrm{PBC}$, which is based on Port-Controlled Hamiltonian (PCH) framework. The main point of the IDA-PBC is to assign a desired energy storage function with respect to the desired equilibrium point by modifying the desired interconnection matrix, damping matrix, and control law (called energy reshaping) [18], [19]. Unlike most nonlinear control methods that focus on the signal, the PBC considers the controller design from the energy point of view which is the essential attribute of the physical system. The advantage of the IDA-PBC over other nonlinear control methods is that this approach utilizes the physical structure and considers the energy relationship of the system. The stability of the individual stage is guaranteed using the Hamiltonian function (energy storage function) as a Lyapunov function. After, thanks to the PCH framework, the IDA-PBC can work in a superposition manner. It relies on decomposing the system into multiple separate subsystems, then the whole system behavior is obtained by superimposing the energies of the subsystems [23]. The asymptotic stability of the whole system can be guaranteed by using the passivity property when several stable and passive ensured subsystems are integrated into the proposed system [21]. Therefore, the controller design and stability analysis only need to be developed and implemented at the subsystem level.

In accordance with the Objective 3), zero steady-state error between the state variable and the reference is to be achieved even when the sustained deviation from the standard value exists in the model parameter. The presence of the integrator is one of the most practical methods utilized for eliminating steady-state errors. In [24], an outer loop PI controller, complementary with the IDA-PBC approach, is introduced to alleviate the steady-state output voltage error. However, this PI controller is not included in the passivity and stability proof. Besides, in general, eliminating steady-state errors by using integrators may degrade other system performance, including dynamic response, phase margin, and loop bandwidth. This is because the utilization of the integrator will have coupled interactions with other control behavior [25]. Another practical method is the use of observers. In [25], a disturbance observer is introduced to a DC/DC buck converter to correct the errors caused by disturbances and uncertainties, which eventually leads to the desired offset-free tracking performance. Moreover, a disturbance observer for boost converter [26] and a reducedorder state observer for buck converter [27] are introduced. The results show that the steady-state errors under both methods can be eliminated. 
TABLE I

LiterATURE REVIEW OF RECENT APPROACHES AND GENERAL COMPARISON

\begin{tabular}{|c|c|c|c|}
\hline Control Objectives & Subclass & Upside & Downside \\
\hline \multirow[t]{2}{*}{ Objective 1) } & $\begin{array}{l}\text { Nonlinear control methods, for example, } \\
\text { flatness-based control [11], sliding-mode } \\
\text { control [12], and model predictive control } \\
\text { [14] for boost converter, Lyapunov-based } \\
\text { control [13] and passivity-based control } \\
\text { [19] for boost converter cascaded with } L C \\
\text { filter, passivity-based control for boost and } \\
\text { buck converters [15]. }\end{array}$ & $\begin{array}{l}\text { - High robustness properties; } \\
\text { - Good dynamic responses; } \\
\text { - Good generalization capability. }\end{array}$ & $\begin{array}{l}\text { - Relatively high computational } \\
\text { requirements compared to the } \\
\text { linear control approach; } \\
\text { - Not easily followed by engineers. }\end{array}$ \\
\hline & Linear control methods, such as PI control. & $\begin{array}{l}\text { - Low computational requirements; } \\
\text { - Simple and easy implementation; } \\
\text { - Easily followed by engineers. }\end{array}$ & $\begin{array}{l}\text { - Less robustness compared to } \\
\text { nonlinear control approaches; }\end{array}$ \\
\hline Objective 2) & $\begin{array}{l}\text { Passivity-based control with passivity } \\
\text { property [17]-[23]. }\end{array}$ & $\begin{array}{l}\text { - The whole system stability can be } \\
\text { guaranteed due to the passivity } \\
\text { property. }\end{array}$ & $\begin{array}{l}\text { - Sensitive to model accuracy and } \\
\text { noise; } \\
\text { - Need a large number of sensors. }\end{array}$ \\
\hline \multirow[b]{2}{*}{ Objective 3) } & Integrator or extra PI regulation term [24]. & $\begin{array}{l}\text { - Simple and easy implementation; } \\
\text { - Accuracy. }\end{array}$ & $\begin{array}{l}\text { - Coupled interactions with other } \\
\text { control behavior. }\end{array}$ \\
\hline & $\begin{array}{l}\text { Observers, for example, disturbance } \\
\text { observer [25] and reduced-order state } \\
\text { observer [27] for buck converter, and } \\
\text { disturbance observer [26] for boost } \\
\text { converter. }\end{array}$ & $\begin{array}{l}\text { - Good dynamic performance; } \\
\text { - Accuracy. }\end{array}$ & $\begin{array}{l}\text { - Relatively high computational } \\
\text { requirements; } \\
\text { - Not simple for implementation. }\end{array}$ \\
\hline Objective 4) & $\begin{array}{l}\text { Observers, for example, Kalman filter [31] } \\
\text { for buck converter, Luenberger observer } \\
\text { [32] and sliding mode observer [33] for } \\
\text { boost converter, state observer for boost } \\
\text { converter cascaded with } L C \text { filter [13]. }\end{array}$ & $\begin{array}{l}\text { - Good dynamic performance; } \\
\text { - Accuracy. }\end{array}$ & $\begin{array}{l}\text { - Relatively high computational } \\
\text { requirements; } \\
\text { - Not simple for implementation. }\end{array}$ \\
\hline
\end{tabular}

Besides, an underlying requirement of the controller design is to maintain the Objective 4) over as large a stability margin as possible. The power density improvement is one of the objectives in on-board microgrids. The reduction of the number of sensors can offer a cost-effective solution to achieve this mission [28]. To this end, many estimation techniques have already been published for DC/DC power converters to realize sensorless control. For example, the Extended Kalman filter is a widely used observer in industrial applications [29]. In [30], a current estimation technique using the extended Kalman filter for a boost converter is introduced. No direct inductor current measurement is needed in this work. In [31], authors introduce a Luenberger observer based on current estimation, and apply it to a boost converter. All the current sensors for MPPT algorithm are removed. This method tracks the power of a PV system without using any current sensor. [32] proposes a sliding mode observer based on an enlarged state model. The source voltage and load resistance of the boost converter is estimated by the proposed observer. In [13], the input current and the losses in a set of $L C$ filter-boost converter are estimated. The observer combined with Lyapunov-based control is implemented to guarantee the stability of the system. Overall, the above discussion on the four control objectives can be generally summarized in Table I.

However, the PBC approach is naturally incapable of meeting Objective 3) and Objective 4). The knowledge of the precise model and relatively large demand for sensors limit its development in electrified transportation applications. As can be seen in [15] and [33], when the IDA-PBC is applied to a boost converter or a buck converter, four sensors must be used. Besides, the final control law is related to the parameters of the $\mathrm{DC} / \mathrm{DC}$ converter, such as the equivalent input series resistance. Indeed, these parameters are difficult to know accurately in practice, and they also change over time. So, the existence of steady-state error is inevitable. Thus, the solution to solve the drawbacks of the conventional IDA-PBC, i.e. cannot naturally satisfy Objective 3) and Objective 4), is of interest. The observer is a good candidate for compensating steady-state errors and reducing the number of sensors. In [34], an adaptive nonlinear state observer is proposed and validated both on boost converter and isolated boost converter. The comparison results show this observer has better performance than an Extended Kalman filter and a Luenberger observer.

To achieve the aforementioned control objectives, this paper proposes to complement the state observer, which inspired by [34], to the modified IDA-PBC methodology.

The main purpose of this paper is to address a new PBC controller and observer, which are designed simultaneously based on the Hamiltonian framework and Lyapunov criterion. Large-signal stability is proved via combining Hamiltonian function with the observer estimation error as the Lyapunov candidate function. As compared with the observer mentioned earlier in [34], in this work, uncertainties, input voltage, and 
output current are estimated together to reduce the number of sensors.

In this paper, a DC/DC boost converter application example is implemented, to demonstrate the validity of the proposed approach. Still, the proposed controller and observer can be easily adapted to other power conversion structures, such as $\mathrm{DC} / \mathrm{AC}$ converters and $\mathrm{AC} / \mathrm{DC}$ converters.

The rest of this paper is organized as follows: Section II describes the studied system and gives its $\mathrm{PCH}$ models. Section III proposes the generalized controller and observer, with its large-signal stability proof. Then, Section IV details the implementation example of the DC/DC boost converter with CPL. Results without parameter uncertainties are given in Section V. And results with parameter uncertainties are shown in Section VI.

\section{PROBLEM DESCRIPTION}

As described earlier, the model and parameters accuracy play an important role in obtaining satisfying results for the PBC approach. These will seriously affect system performance. The equivalent circuit-type models of the DC/DC boost converter are usually published in the literature as seen in Fig. 1.

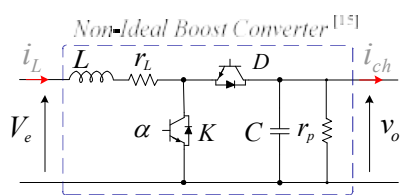

(a)

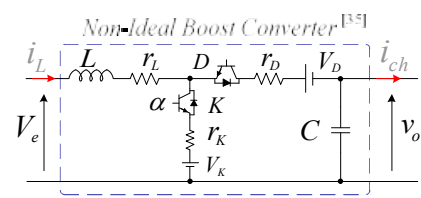

(b)

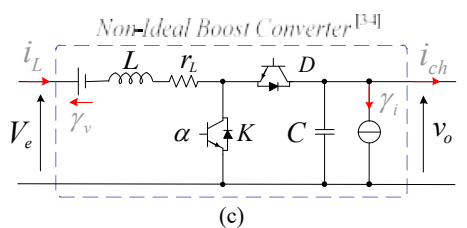

Fig. 1. DC/DC boost converter model. (a) Non-ideal model in [15]. (b) Nonideal model in [35]. (c) Non-ideal model in [34].

As can be seen in the previous work in [15], a type of nonideal model is used for the IDA-PBC. In that case, all the circuit parameters are assumed to be accurately measured in the laboratory and all the un-modeled losses are taken into account thanks to the constant equivalent series resistance $r_{L}$ and the constant parallel resistance $r_{p}$. However, in the general case, this assumption cannot be satisfied. In industrial applications, these parameters and losses vary over time and the operating conditions. This assumption applies only to a small range of operating points. Here, the control method given in [15] is reappeared with inaccuracy parameters and converter losses. The power of the Constant Power Load (CPL) steps from $1 \mathrm{~kW}$ to $3 \mathrm{~kW}$, and the results are illustrated in Fig. 2. An output voltage deviation is emerged due to these parameter uncertainties and internal losses. Moreover, there are four sensors used in this work.

A more precise model is introduced in Fig. 1(b), the parasitic components are considered in this model [35]. $r_{L}, r_{K}$, and $r_{D}$ are the parasitic resistances of inductance $L$, switch $K$, and diode $D$, respectively. The voltage drops on switch $K$ and diode $D$ are $V_{K}$ and $V_{D}$. Even though this model is more accurate, it is still not possible to describe the online knowledge of the converter behavior. Because all the losses are not constant in practice. Moreover, only conduction losses are considered in this model, and it is still impossible to consider semiconductor switching losses and magnetic circuit power losses. Furthermore, this equivalent circuit is too complicated to fit in $\mathrm{PCH}$ framework. It makes the IDA-PBC not applicable.
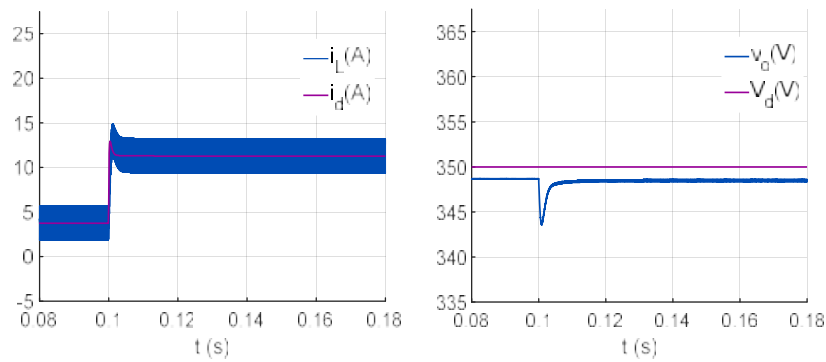

Fig. 2. Current (left) and voltage (right) responses of the boost converter with inaccuracy parameters and converter losses using the IDA-PBC in [15].

In Fig. 1(c), an additional variable voltage source $\gamma_{v}$, and an additional variable current source $\gamma_{i}$ are used to counterbalance the errors between the actual system and its model. Thus, these additional sources are directly equivalent to all uncertainties, including internal losses, parameter variations, measurement offsets, etc. Principal losses which are taken into account are conduction losses, semiconductors switching losses, hysteresis losses, and eddy current core losses. Any other loss through the converter is also taken into account [34]. Therefore, only two variable parameters are added to counterbalance all uncertainties in the system. These equivalent sources vary with the operating point. Compared to the model in Fig. 1(a) with constant equivalent losses parameters, the complexity of the model has not increased, but online knowledge can be achieved through the observer. Compared to the model in Fig. 1(b), fewer parameters are used to include more types of losses. More importantly, The PCH framework is easy to apply to this model. It is why this equivalent model is selected for the controller and observer design in this paper.

\section{GENERALIZED CONTROLLER AND OBSERVER}

\section{A. Considered System and Port-controlled Hamiltonian Models Applied}

The generalization of the $\mathrm{PCH}$ system with dissipation can be presented utilizing the following expression [19].

$$
\dot{x}=[J(x)-R(x)] \frac{\partial H}{\partial x}(x)+\beta(x) u+\xi
$$

where $J(x)$ is known as the interconnection matrix (skewsymmetric) and $R(x)$ is called the dissipation matrix (positive semidefinite). $H(x) \geq 0$ stands for the internal energy accumulation in the system called Hamiltonian function. $u$ is the control input of the system. $\beta(x)$ is the input matrix and $\xi$ corresponds to the disturbances. 
Here, the $\mathrm{PCH}$ form in (1) is rewritten as (2). $\xi$ can be replaced by the product of the coefficient matrix $g(x)$ and the actual disturbance variable $\rho$. The disturbance is supposed to vary much slower than the state variable, i.e., $\dot{\rho}=0$ [34].

$$
\dot{x}=[J(x)-R(x)] \frac{\partial H}{\partial x}(x)+\beta(x) u+g(x) \rho
$$

\section{B. Observer Definition}

Based on the above model, the following observer is proposed,

$$
\left\{\begin{array}{l}
\dot{\hat{x}}=[J(x)-R(x)] \frac{\partial H}{\partial x}(x)+\beta(x) u+g(x) \hat{\rho}-k_{s}(\hat{x}-x) \\
\dot{\hat{\rho}}=-\eta_{1}(\hat{x}-x)-k_{p}(\dot{\hat{x}}-\dot{x})+\eta_{2}
\end{array}\right.
$$

where $x$ is the measured state variable and $\hat{x}$ represents the estimation value of $x . \hat{\rho}$ is the estimation of the unknown disturbance and functions $J(x), R(x), \frac{\partial H}{\partial x}(x), \beta(x)$ and $g(x)$ are supposed well known. $k_{s}$ and $k_{p}$ are the observer gain matrices to be determined while $\eta_{1}$ and $\eta_{2}$ are two functions to be defined. The observer design procedure will be detailed in Section III.D. However, as we will see, the observer is asymptotically stable even if $k_{p}=0$ (no derivative terms in the observer). This statement has been confirmed by simulation and experimentation. Meanwhile, to achieve exponential stability, this term is included in the proposed observer. The estimation errors $\varepsilon_{x}$ and $\varepsilon_{\rho}$ can be defined as follows

$$
\left\{\begin{array}{l}
\varepsilon_{x}=\hat{x}-x \\
\varepsilon_{\rho}=\hat{\rho}-\rho
\end{array}\right.
$$

The derivative of the estimation errors $\varepsilon_{x}$ and $\varepsilon_{\rho}$ can be calculated, respectively, as follows,

$$
\begin{aligned}
& \dot{\varepsilon}_{x}=g(x) \varepsilon_{\rho}-k_{s} \varepsilon_{x} \\
& \dot{\varepsilon}_{\rho}=-\eta_{1} \varepsilon_{x}-k_{p} \dot{\varepsilon}_{x}+\eta_{2}
\end{aligned}
$$

\section{Controller Design}

The general concept of IDA-PBC methodology based on $\mathrm{PCH}$ is introduced in [36], which is to assign the closed-loop Hamiltonian function $H_{d}(x)=0.5 \cdot\left(x-x_{d}\right)^{T} Q\left(x-x_{d}\right)$ with the desired equilibrium point $x_{d}$, the desired interconnection matrix $J_{d}(x)$, and damping matrix $R_{d}(x)$. $Q$ is the energy storage element matrix (positive-definite). In this respect, $H_{d}(x)$ should satisfy an isolated minimum at the desired equilibrium point to ensure system stability.

It is worthwhile to mention that, the conventional IDA-PBC is not satisfied with the on-board power converter system with variable CPL [19]. In this application, the desired equilibrium point $x_{d}$ is related to the actual operating conditions and is no longer a constant value. Therefore, the proposed control approach is inspired by the modified IDA-PBC introduced in [19]. Considering that $x_{d}$ is only a function of the unknown parameter $\hat{\rho}$, i.e. $x_{d}=f(\hat{\rho})$. The desired target is to define a control law $u$ that the closed-loop system dynamics can be expressed as

$$
\dot{x}-\dot{x}_{d}=\left[J_{d}(x)-R_{d}(x)\right] \frac{\partial H_{d}}{\partial\left(x-x_{d}\right)}(x)-g(x)(\hat{\rho}-\rho)
$$

where $\dot{x}_{d}$ is computed by

$$
\dot{x}_{d}=\frac{\partial x_{d}}{\partial \hat{\rho}} \cdot \dot{\hat{\rho}}
$$

Towards this end, the final state-feedback control law $u$ can be calculated by the following expression, which is derived from (2) and (7),

$$
\begin{aligned}
{[J(x)-R(x)] \frac{\partial H}{\partial x} } & (x)+\beta(x) u+g(x) \hat{\rho} \\
= & {\left[J_{d}(x)-R_{d}(x)\right] \frac{\partial H_{d}}{\partial\left(x-x_{d}\right)}(x)+\dot{x}_{d} }
\end{aligned}
$$

It is worthwhile to note that, the control law $u$ is the only unknown in (9). To avoid (9) fails to have a unique solution, some variables in the closed-loop interconnection matrix $J_{d}$ can be added to provide an additional degree of freedom. If the solution of (9) exists, it leads to $u=F\left(x, x_{d}, \dot{x}_{d}, \hat{\rho}\right)$.

Moreover, there are three main differences between the control law (9) in this paper and the control law (3) in [15].

1) The control law (3) in [15] is based on conventional IDA$\mathrm{PBC}$. In this work, the proposed control is inspired by the modified IDA-PBC introduced in [19].

2) In the control law (3) in [15], all the losses are mapped to a constant parameters $r_{L}$ and $r_{p}$ in the dissipation matrix $R$. In the new control law (9), the losses are spread out between $r_{L}$ and unknown disturbance vector $\rho$ which is estimated online. This is related to the control Objective 3) in Section I.

3) In the control law (3) in [15], the external disturbance should be measured through the sensor. In the control law (9) here, external and internal disturbances are estimated together by the observer. This is related to the control Objective 4) in Section I.

\section{Stability Analysis}

To demonstrate the convergence of the observer and ensure the stability of the whole system. Considering the Lyapunov function candidate $V$ defined as

$$
V=H_{d}(x)+\frac{1}{2} \varepsilon_{x}{ }^{\mathrm{T}} \varepsilon_{x}+\frac{1}{2} \varepsilon_{\rho}{ }^{\mathrm{T}} \varepsilon_{\rho} \geq 0
$$

The derivative of the function $V$ can be expressed as

$$
\begin{aligned}
\dot{V}= & -\left(x-x_{d}\right)^{\mathrm{T}} Q^{\mathrm{T}} R_{d} Q\left(x-x_{d}\right)-\left(\frac{\partial H_{d}}{\partial\left(x-x_{d}\right)}\right)^{\mathrm{T}} \cdot g(x) \cdot \varepsilon_{\rho} \\
& +\varepsilon_{x}^{\mathrm{T}}\left(g(x) \cdot \varepsilon_{\rho}-k_{s} \cdot \varepsilon_{x}\right) \\
& +\varepsilon_{\rho}^{\mathrm{T}}\left(-\eta_{1} \cdot \varepsilon_{x}-k_{p} \dot{\varepsilon}_{x}+\eta_{2}\right)
\end{aligned}
$$

Afterward, by introducing $k_{i}=k_{p} \cdot g(x)$ and adopting the following conditions: 


$$
\begin{aligned}
& k_{s}>0, \quad k_{i}>0, \quad R_{d}>0, \quad \eta_{1}=k_{s} \cdot k_{p}+g^{\mathrm{T}}(x), \\
& \eta_{2}=g(x) \frac{\partial H_{d}}{\partial\left(x-x_{d}\right)}(x),
\end{aligned}
$$

If $\varepsilon_{x} \neq 0, \varepsilon_{\rho} \neq 0, x \neq x_{d}$, it implies,

$$
\begin{aligned}
\dot{V}= & -\left(x-x_{d}\right)^{\mathrm{T}} Q^{\mathrm{T}} R_{d} Q\left(x-x_{d}\right) \\
& -\varepsilon_{x}{ }^{\mathrm{T}} k_{s} \varepsilon_{x}-\varepsilon_{\rho}^{\mathrm{T}} k_{i} \varepsilon_{\rho}<0
\end{aligned}
$$

Therefore, the convergence of the estimated variables to the actual ones is ensured and the considered system is exponentially stable.

Equation (13) is valid in the entire domain defined by the model. In other word, the stability is global and not limited to small-signal variations around the equilibrium point. Thus, the desired equilibrium point is globally stable within the scope defined by the model, i.e. the domain of attraction of the desired equilibrium point is global, which is equal to the validity range of the model. Consequently, large-signal variations will not influence the stability of the system. This statement holds for both controller and observer because their design is based on a proper Lyapunov function. Therefore, the large-signal stability of the entire system is guaranteed.

As for the parameters of the proposed control strategy, there are three parameters, i.e. $R_{d}, k_{s}$, and $k_{i}$, which should be determined when using this control strategy. The following guidelines can be used to select the satisfactory parameter.

$R_{d}$ is used to tune the dynamic performance and directly affects the set-point tracking. Firstly, the proposed control approach is designed based on the Lyapunov stability theorem. In the light of (13), $R_{d}$ is positive-definite. Secondly, the IDAPBC is a model-based control, i.e. the closed-loop PCH model and control parameters need to be determined based on the open-loop PCH model and circuit parameters. If no additional damping assigned, i.e. $R_{d}=R$, the natural damping of the system generally cannot meet the dynamic requirements, e.g. overshoot and settling time. Afterward, the damping value can be increased to meet the requirements, i.e. damping injection. This is to put the eigenvalues of the matrix $-Q^{T} R_{d} Q$ in a domain in the left half complex plane. The real part of this domain is less than $-\sigma_{0}$, where $\sigma_{0}>0$ is a stability margin defined by the designer. Here, the same guidelines as for pole placement can be used. In fact, larger $\sigma_{0}$ means more control effort, so $\sigma_{0}$ should be chosen within $\left[\sigma_{\min }, \sigma_{\max }\right]$, where $\sigma_{\min }$ is the least stability margin required and $\sigma_{\max }$ is to avoid the duty cycle out of the range of $[0,1]$. Otherwise, the duty cycle $d$ saturates at 0 or 1 , and the passivity and stability proofs are no longer satisfied [15]. Moreover, another criterion is associated with the digital implementation of the control algorithm limiting $\sigma_{\max }$. This latter cannot be chosen very large unless the digital controller becomes unstable. These guidelines only provide a range of values that the designer can choose for $R_{d}$. This is also true for $k_{s}$ and $k_{i}$.

The matrices $k_{s}$ and $k_{i}$ are the observer gains adjusting the estimation convergence rate. Like $R_{d}$, they should be positivedefinite to ensure the estimation convergence and the system stability. Moreover, the observer design using pole placement criteria can be used to define $k_{s}$ and $k_{i}$. Indeed, the convergence rate is determined by real parts of the eigenvalues of $k_{s}$ and $k_{i}$. It is well known that the observer dynamic is usually set to be faster than the controller dynamic. Considering this, the real parts of the eigenvalues of $k_{s}$ and $k_{i}$ are selected in a way they are much greater than $\sigma_{0}$ but less than $\sigma_{1}$, where $\sigma_{1} \gg \sigma_{0}>0$ is the observer stability limit due to digital implementation and high-frequency noises. $\sigma_{1}$ is defined by the designer. From this point of view regarding the envelope of time responses and stability margins, the design of the proposed controller and observer is seen in the same way as a pole placement technique.

Moreover, it is worthwhile to note that the relationship between the value of $k_{s}$ and $k_{i}$ is based on the assumption that the dynamics of the disturbance error $\varepsilon_{\rho}$ have to be much slower than the dynamics of the state variable error $\varepsilon_{x}$. This choice involves the design of the matrix $k_{s}$ and the matrix $k_{i}$. The eigenvalues real parts of the matrix $k_{s}$ should be highly greater than those of matrix $k_{i}$. Once the matrix $k_{i}$ is determined, the matrix $k_{p}$ can be calculated by $k_{p}=k_{i} \cdot g^{-1}(x)$ [34].

The proposed observer in (3) can be rewritten as (14) and (15).

$$
\begin{aligned}
& \dot{\hat{x}}=[J(x)-R(x)] \frac{\partial H}{\partial x}(x)+\beta(x) u+g(x) \hat{\rho}-k_{s} \varepsilon_{x} \\
& \dot{\hat{\rho}}=-\left(k_{s} \cdot k_{p}+g^{\mathrm{T}}(x)\right) \varepsilon_{x}-k_{p} \dot{\varepsilon}_{x}+g(x) \frac{\partial H_{d}}{\partial\left(x-x_{d}\right)}(x)
\end{aligned}
$$

The generalized scheme diagram with the proposed controller and observer is given in Fig. 3.

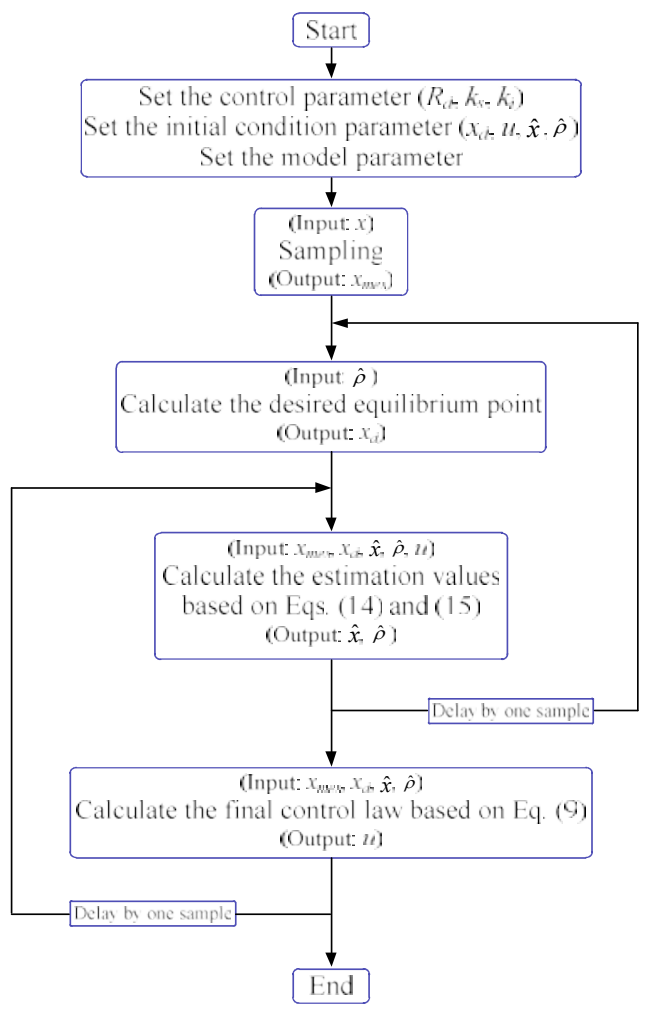

(b) 


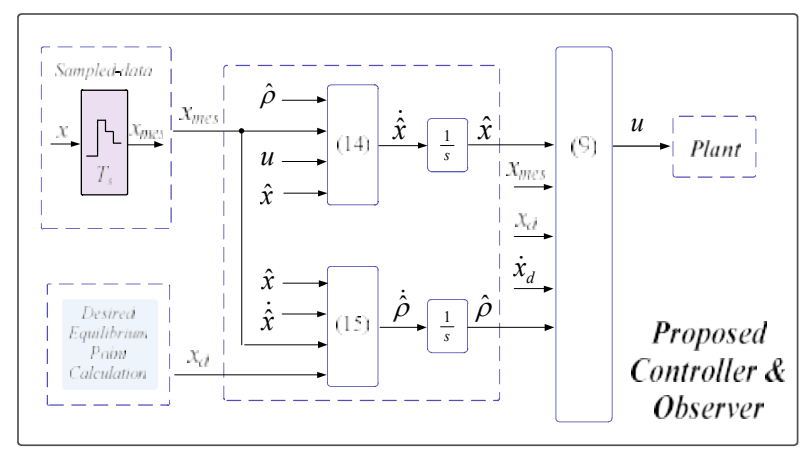

(a)

Fig. 3. Scheme of the proposed controller and observer. (a) Flowchart of the subroutines. (b) Control block diagram.

Moreover, it is worthwhile to mention that, the stability analysis in this paper is based on large-signal stability rather than small-signal stability. The small-signal stability analysis tools are based on small-signal assumption and local linearization. Equations of the system are linearized at the equilibrium point, and the resulting small-signal models can be easily evaluated by using classical eigenvalues and frequency domain techniques (e.g. impedance criterion). Then, engineers can design the controller, e.g. PID, ensuring the stability of the system. The use of the well-known linear analysis and design tools is indeed the advantage of the small-signal stability analysis.

However, there are many disadvantages to small-signal stability. The small-signal stability analysis tools use local linearized models. These latter are only valid in sense of "smallsignal variations" around on operating point or a trajectory. That means, it is not clear how large deviations from the operating point are allowed without affecting the stability analysis. In fact, the stable operation is only ensured in an "area" around the operating point. No accurate indication is given on the size of this area. This is actually a significant drawback. A typical example is the no-load to full-load step test run in onboard microgrids for aircraft. When the step change is applied, the DC-bus voltage might vary significantly so it cannot be considered as a small-signal variation. With large-signal stability analysis, the aim is not only to evaluate the stability of the equilibrium point, but also to determine the domain of attraction, which shows the maximum deviation from the equilibrium point that the system can tolerate [18].

Another significant issue with impedance-based stability analysis of onboard microgrids lies with its very conservative nature. Indeed, this analysis requires restrictions on the input impedance of the load system and the output impedance of the source system. In the framework of microgrids, the number of sources and load subsystems is large. This makes those restrictions very tight. To meet those requirements, the design of the controller becomes very conservative at the cost of either bulky capacitors, or low dynamic control loops, or both. But this will increase the cost and reduce $\mathrm{kW} / 1$ and $\mathrm{kW} / \mathrm{kg}$ numbers. However, this is not acceptable for high performance electrified transportation systems.
Indeed, the large-signal stability proof implies the smallsignal stability, but the other way around is not sure [37], [38]. Since a large-signal stable system is naturally small-signal stable, the method proposed in this paper can indeed solve the small-signal stability issue, so no small-signal stability analysis is required. However, we agree that the large-signal stability is more difficult to prove, but the key point is that the domain of attraction can be given to strictly ensure the convergence property of the closed-loop system. On the other hand, we admit that the large-signal stability could be in some cases very conservative, too. That's why we look for the least conservative approach improving the system performances including $\mathrm{kW} / \mathrm{l}$ and $\mathrm{kW} / \mathrm{kg}$.

\section{VALIDATION ON DC/DC BOOST CONVERTER}

The studied system is illustrated in Fig. 4. Considering the system is supplied by a high voltage DC bus which delivers $270 \mathrm{~V}$ that will be considered constant in this paper. A DC/DC boost converter supplying CPL is regulated by the proposed controller and observer.

The model uncertainties (mainly refer to losses) and parameters uncertainties in the converter are considered as the equivalent voltage source $\gamma_{v}$ and the equivalent current source $\gamma_{i}\left(\gamma_{v}\right.$ and $\gamma_{i}$ also named internal disturbances). It is worth noting that the equivalent series resistance (ESR) of the output capacitor can be considered as a part of internal losses, and then included in these equivalent sources. Therefore, the use of the proposed observer allows considering a simplified model for the design of the controller. The modeling error will be rejected by the proposed observer.

It is worthwhile to note that, the ideal CPL does not exist in practice, and the tightly regulated load converter exhibits CPL behavior. Therefore, it is reasonable and attainable to replace CPL with a tightly regulated DC/DC converter. In this paper, a buck converter using sliding mode control is implemented to emulate the CPL behavior.

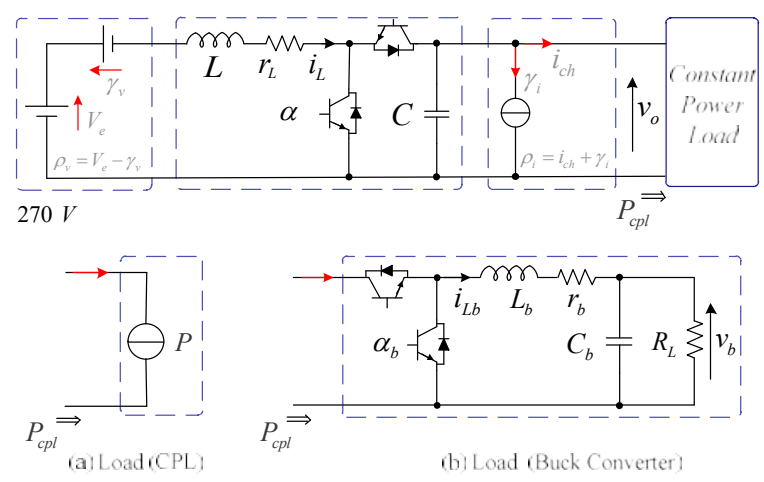

Fig. 4. Boost converter with CPL - Equivalent structure of the proposed model.

The $\mathrm{DC} / \mathrm{DC}$ boost converter with the equivalent variables can be described as, 


$$
\left\{\begin{array}{l}
L \frac{d i_{L}}{d t}=V_{e}-r_{L} i_{L}-(1-d) v_{o}-\gamma_{v} \\
C \frac{d v_{o}}{d t}=(1-d) i_{L}-i_{c h}-\gamma_{i}
\end{array}\right.
$$

where $d$ represents the duty cycle corresponding to the PWM output signal $\alpha$. The total energy stored in the converter is denoted as the Hamiltonian function:

$$
H(x)=\frac{L}{2} x_{1}^{2}+\frac{C}{2} x_{2}^{2}=\frac{1}{2} x^{\mathrm{T}} Q x
$$

where, $Q=\operatorname{diag}(L, C)$ and $x=\left[x_{1}, x_{2}\right]^{T}=\left[i_{L}, v_{o}\right]^{T}$ indicate the energy storage element matrix and the state variable, respectively. Moreover, $V_{e}$ and $i_{c h}$ can be considered as external disturbances, $\gamma_{v}$ and $\gamma_{i}$ can be considered as internal disturbances. Therefore, based on the differential equation in (16), $\rho_{v}=V_{e}-\gamma_{v}$ and $\rho_{i}=i_{c h}+\gamma_{i}$ can be defined as the disturbance of the boost converter. As mentioned earlier, it is assumed that the disturbance varies much slower than the state variable. Compared to [34], the series resistance $r_{L}$ is considered in the model, so the parameters $\gamma_{v}$ and $\gamma_{i}$ are less dependent on the state variable. Compared to [13] and [34], the internal and external disturbances are estimated together. This further alleviates the dependence of the disturbance on the state variable. According to this assumption, the equation (16) can be rewritten as

$$
\left\{\begin{array}{l}
L \frac{d i_{L}}{d t}=-r_{L} i_{L}-(1-d) v_{o}+\rho_{v} \\
C \frac{d v_{o}}{d t}=(1-d) i_{L}-\rho_{i}
\end{array}\right.
$$

According to (2) and (18), the dynamics of the boost converter are defined by PCH models of the form

$$
\left[\begin{array}{c}
\dot{x}_{1} \\
\dot{x}_{2}
\end{array}\right]=\left[\begin{array}{cc}
\frac{-r_{L}}{L^{2}} & \frac{-1}{L C} \\
\frac{1}{L C} & 0
\end{array}\right] \frac{\partial H}{\partial x}(x)+\left[\begin{array}{c}
\frac{x_{2}}{L} \\
\frac{-x_{1}}{C}
\end{array}\right] d+\left[\begin{array}{cc}
\frac{1}{L} & 0 \\
0 & \frac{-1}{C}
\end{array}\right]\left[\begin{array}{c}
\rho_{v} \\
\rho_{i}
\end{array}\right]
$$

As mentioned earlier, when the conventional IDA-PBC is applied to the boost converter, four sensors must be used in the previous work [15]. It includes the inductor current $i_{L}$, output voltage $v_{o}$, input voltage $V_{e}$, and output current $i_{c h}$. In this work, no input voltage sensor and no output current sensor are employed. The unknown parameters $\rho_{v}$ and $\rho_{i}$ are estimated online by the proposed observer. The parameters of the observer are tuned experimentally to obtain better performances. $k_{s}$ and $k_{i}$ are chosen as the following positive-definite diagonal matrices.

$$
k_{s}=\left[\begin{array}{cc}
3000 & 0 \\
0 & 3000
\end{array}\right] \quad k_{i}=\left[\begin{array}{cc}
100 & 0 \\
0 & 100
\end{array}\right]
$$

Moreover, consider the system described in (19) has the desired equilibrium point $x_{d}=\left[x_{1 d}, x_{2 d}\right]^{T}=\left[i_{d}, V_{d}\right]^{T}$ which satisfies (7). The desired energy accumulation in the converter is expressed as the closed-loop Hamiltonian function $H_{d}(x)$

$$
H_{d}(x)=\frac{L}{2}\left(x_{1}-x_{1 d}\right)^{2}+\frac{C}{2}\left(x_{2}-x_{2 d}\right)^{2}=\frac{1}{2}\left(x-x_{d}\right)^{\mathrm{T}} Q\left(x-x_{d}\right)
$$

In this paper, the desired closed-loop interconnection matrix (skew-symmetric) and the damping matrix (positive-definite) are chosen as follow

$$
J_{d}=\left[\begin{array}{cc}
0 & \frac{-1}{L C}-K(x) \\
K(x)+\frac{1}{L C} & 0
\end{array}\right] \quad R_{d}=\left[\begin{array}{cc}
\frac{r_{1}}{L^{2}} & 0 \\
0 & \frac{r_{2}}{C^{2}}
\end{array}\right]
$$

where $r_{1}$ and $r_{2}$ are damping parameters to be defined by the designer. And $K(x)$ is an additional degree of freedom to make sure the equation (9) has a unique solution. The resulting closed-loop system, satisfying (7), is

$$
\left[\begin{array}{c}
\dot{x}_{1} \\
\dot{x}_{2}
\end{array}\right]=\left[\begin{array}{cc}
\frac{-r_{1}}{L^{2}} & \frac{-1}{L C}-K(x) \\
K(x)+\frac{1}{L C} & \frac{-r_{2}}{C^{2}}
\end{array}\right] \frac{\partial H_{d}}{\partial\left(x-x_{d}\right)}(x)-\left[\begin{array}{cc}
\frac{1}{L} & 0 \\
0 & \frac{-1}{C}
\end{array}\right]\left[\begin{array}{c}
\hat{\rho}_{v}-\rho_{v} \\
\hat{\rho}_{i}-\rho_{i}
\end{array}\right]+\left[\begin{array}{c}
\dot{i}_{d} \\
\dot{V}_{d}
\end{array}\right]
$$

The main regulation objective for the $\mathrm{PBC}$ controller is to keep the output voltage constant. In this work, the desired output voltage $V_{d}\left(V_{\text {ref }}\right)$ is set to $350 \mathrm{~V}$. The desired current $i_{d}$ is derived by the power conservation

$$
\left\{\begin{array}{l}
i_{d}=\frac{\hat{\rho}_{v}}{2 r_{L}}\left(1-\sqrt{1-\frac{P}{P_{\max }}}\right) \\
P_{\max }=\frac{\hat{\rho}_{v}^{2}}{4 r_{L}}
\end{array}\right.
$$

It is worthwhile to mention that the load power varies over time without notifying the controller. It relies on the equilibrium point and operating condition. Therefore, the parameter $P$ in (24) is unknown in practice, except we measure or estimate it. Here, the power $P$ is estimated by the product of $\hat{\rho}_{i}$ and $V_{d}\left(P=\hat{\rho}_{i} \cdot V_{d}\right)$, where $V_{d}$ is the desired output voltage fixed by its set-point $V_{\text {ref. }}$. Therefore, if there is a sudden power change in the system, the controller and the observer will act simultaneously under the constraints of equation (13) to bring all errors $\left(\varepsilon_{x}, \varepsilon_{p}\right.$ and $\left.x-x_{d}\right)$ to zero.

The derivative of the desired equilibrium point $x_{d}$ is expressed as

$$
\left[\begin{array}{c}
\dot{i}_{d} \\
\dot{V}_{d}
\end{array}\right]=\left[\begin{array}{ll}
\frac{\partial i_{d}}{\partial \hat{\rho}_{v}} & \frac{\partial i_{d}}{\partial \hat{\rho}_{i}} \\
\frac{\partial V_{d}}{\partial \hat{\rho}_{v}} & \frac{\partial V_{d}}{\partial \hat{\rho}_{i}}
\end{array}\right] \dot{\hat{\rho}}
$$

Consequently, and from equation (9), the control law for the converter in Fig. 4 is derived from 


$$
\begin{aligned}
& {\left[\begin{array}{cc}
\frac{-r_{L}}{L^{2}} & \frac{-1}{L C} \\
\frac{1}{L C} & 0
\end{array}\right]\left[\begin{array}{cc}
L & 0 \\
0 & C
\end{array}\right]\left[\begin{array}{c}
x_{1} \\
x_{2}
\end{array}\right]+\left[\begin{array}{c}
\frac{x_{2}}{L} \\
\frac{-x_{1}}{C}
\end{array}\right] d+\left[\begin{array}{cc}
\frac{1}{L} & 0 \\
0 & \frac{-1}{C}
\end{array}\right]\left[\begin{array}{l}
\hat{\rho}_{v} \\
\hat{\rho}_{i}
\end{array}\right] } \\
&= {\left[\begin{array}{cc}
\frac{-r_{1}}{L^{2}} & \frac{-1}{L C}-K(x) \\
K(x)+\frac{1}{L C} & \frac{-r_{2}}{C^{2}}
\end{array}\right]\left[\begin{array}{cc}
L & 0 \\
0 & C
\end{array}\right]\left[\begin{array}{l}
x_{1}-x_{1 d} \\
x_{2}-x_{2 d}
\end{array}\right]+\left[\begin{array}{c}
\dot{x}_{l d} \\
\dot{x}_{2 d}
\end{array}\right] }
\end{aligned}
$$

As for the variable $K(x)$, it is only used for providing an additional degree of freedom. To show it, let us suppose $x \in R^{n}$ and $d \in R^{p}$, so (26) can be seen as a set of $n$ equations with $p$ unknowns. In power electronic devices, if $n \neq p$, the solution ( $p$ unknowns satisfying $n>p$ equations) does not exist. To ensure that the control design admits one unique solution, this paper introduces a set of variables $K \in R^{n-p}$ to obtain a non-singular system. Here, $n=2$ and $p=1$. Therefore, a new adaptive variable $K(x)$ is introduced in $J_{d}$ to establish the internal links in the $\mathrm{PCH}$ system and to obtain the unique control law.

\section{RESUlTS WiTHOUT PARAMETERS UNCERTAINTIES}

To assess the effectiveness of the proposed controller and observer, both numerical simulation and experimental tests are carried out. The parameters used in this work are summarized in Table II.

TABLE II

SYSTEM PARAMETERS USING IN THE BOOST CONVERTER

\begin{tabular}{ccl}
\hline \hline Parameter & Quantity & Value \\
\hline$V_{e}$ & DC-bus input voltage & $270 \mathrm{~V}$ \\
$V_{\text {ref }}$ & Output voltage reference & $350 \mathrm{~V}$ \\
$L$ & Inductance & $1 \mathrm{mH}$ \\
$r_{L}$ & Inductor resistance & $0.2 \Omega$ \\
$C$ & Capacitance & $560 \mu \mathrm{F}$ \\
$F_{S}$ & Frequency & $20 \mathrm{kHz}$ \\
\hline \hline
\end{tabular}

A $3 \mathrm{~kW} 270-350 \mathrm{~V}$ experimental setup as shown in Fig. 5 is built in the laboratory to obtain experimental results. The control algorithm is conducted based on MATLAB/Simulink and then coded into dSPACE (ds1103) real-time control card.

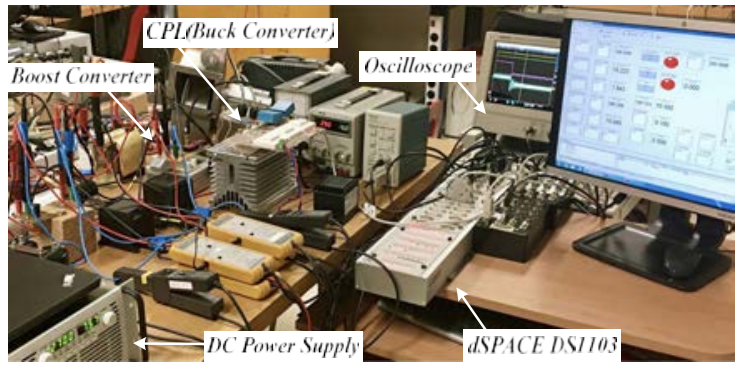

Fig. 5. 3 kW 270-350 V experimental setup.

Also, to verify the possibility of the control algorithm running on a regular embedded processor and whether the complexity of the control law is increased compared to the conventional IDA-PBC, a TI-DSP (TMS320F28335) is used to implement the proposed control algorithm. Through the CCS integrated development environment, the execution time of the proposed control algorithm with TMS320F28335 is $22.07 \mu$ s.
Thus, the proposed control law is feasible to use for industrial applications. Compared with the conventional IDA-PBC, the complexity of the control law has not significantly increased.

As previously mentioned, on-board power converter systems are always accompanied by the constantly changing power load. In practice, the power variation in CPL always occurs. Thus, it is essential to verify the proposed approach in response to these kinds of variations. In this section, suppose the parameters are completely known. The nominal values of the parameters are used in the control law.

The simulation and experimental results under step the CPL power from $1 \mathrm{~kW}$ to $3 \mathrm{~kW}$ are presented in Figs. 6-9. The results show that, without $\left(R=R_{d}\right)$ and with $\left(R \neq R_{d}\right)$ damping injection, the estimated values converge to the actual ones and exactly track their desired value in all cases. There are no steady-state errors for the state variables, especially the output voltage. Also, the system does not have any instability issues in both steadystate and transient. Indeed, from a mathematical point of view, as indicated in (13), high damping value is better for the system stability margin. However, as can be seen from Fig. 6, $R_{d}$ are chosen equal to their nominal values, related to the parameters defined in Table II. This choice does not increase the system stability margin. But the results show that the system does not have any instability issue, because the system is already stable with these nominal values. Then, one can increase the damping values from the nominal values to obtain satisfactory performance, and at the same time, the stability margin is also increased accordingly. Therefore, the system will never become unstable.

In Fig. 6, the virtual damping is not injected into the system, the natural damping is utilized in the PBC controller, a relatively long settling time, and large peak overshoot are responded during the transient. Therefore, it is necessary to introduce the damping assignment technique to tune the dynamic performance. The results are illustrated in Fig. 7, Fig. 8, Fig. 9 correspond, respectively, to the cases $r_{l}=1, r_{l}=3, r_{l}=5$.
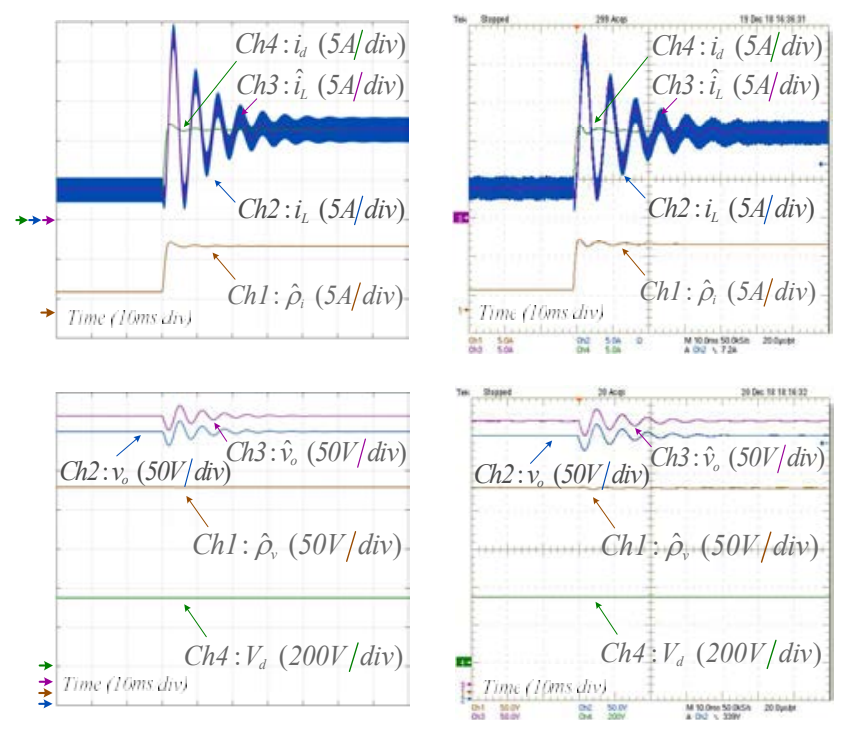

Fig. 6. System response without damping injection when the CPL steps from 1 $\mathrm{kW}$ to $3 \mathrm{~kW}$, simulation (left) and experimental (right) results. 

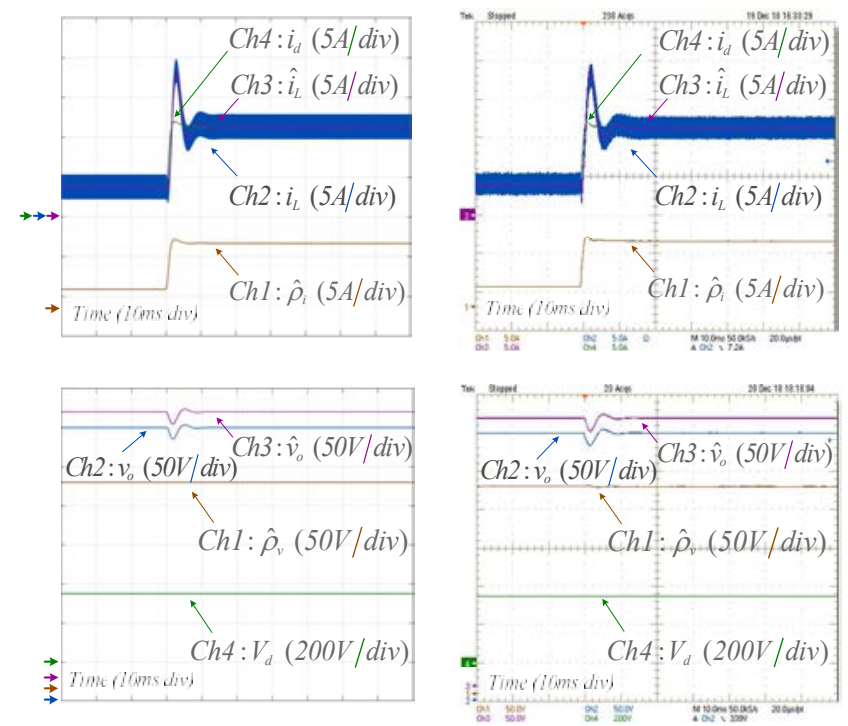

Fig. 7. System response with damping injection when the CPL steps from 1 $\mathrm{kW}$ to $3 \mathrm{~kW}\left(r_{l}=1\right)$, simulation (left) and experimental (right) results.
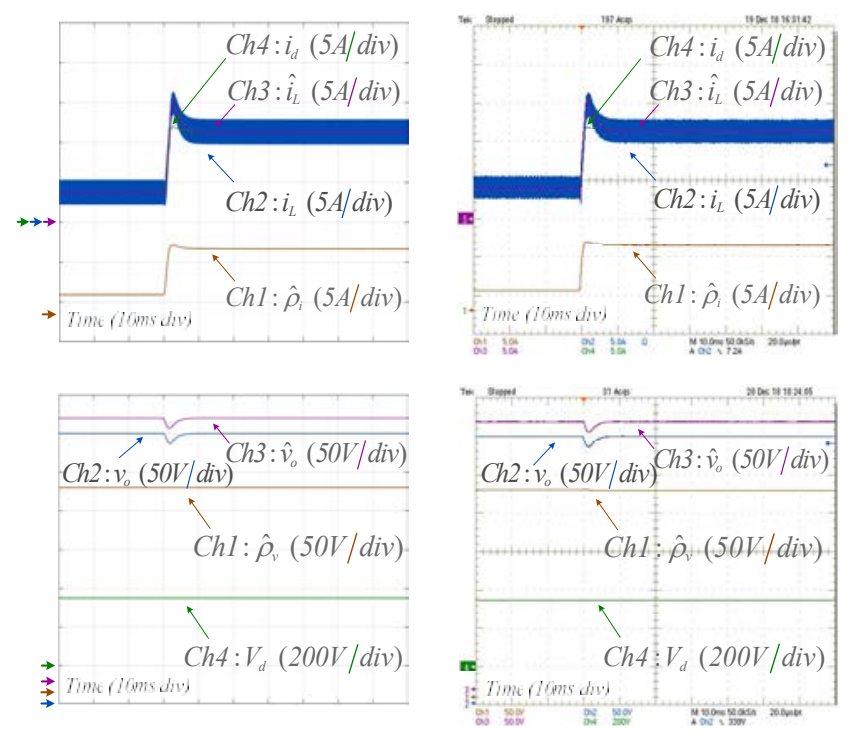

Fig. 8. System response with damping injection when the CPL steps from 1 $\mathrm{kW}$ to $3 \mathrm{~kW}\left(r_{l}=3\right)$, simulation (left) and experimental (right) results.

It can be seen from Fig. 8 , the settling time is about $8 \mathrm{~ms}$ and the peak overshoot of the inductor current is around 0.452 (in percent). Compared with the no damping case, i.e. Fig.6, both the settling time and the overshoot are correspondingly decreased. Statistically speaking, the settling time is reduced by $84 \%$, and the peak overshoot is reduced by $70.8 \%$. Moreover, it should be pointed out that, too much damping will also slow down the system response. Fig. 9 exhibits a $10 \mathrm{~ms}$ settling time and it tunes the peak current overshoot to 0.356 , the decrease in peak overshoot is at the expense of increasing the settling time. Therefore, based on the control objectives, the proper parameters are selected to ensure that the settling time and the overshoot are compromised.
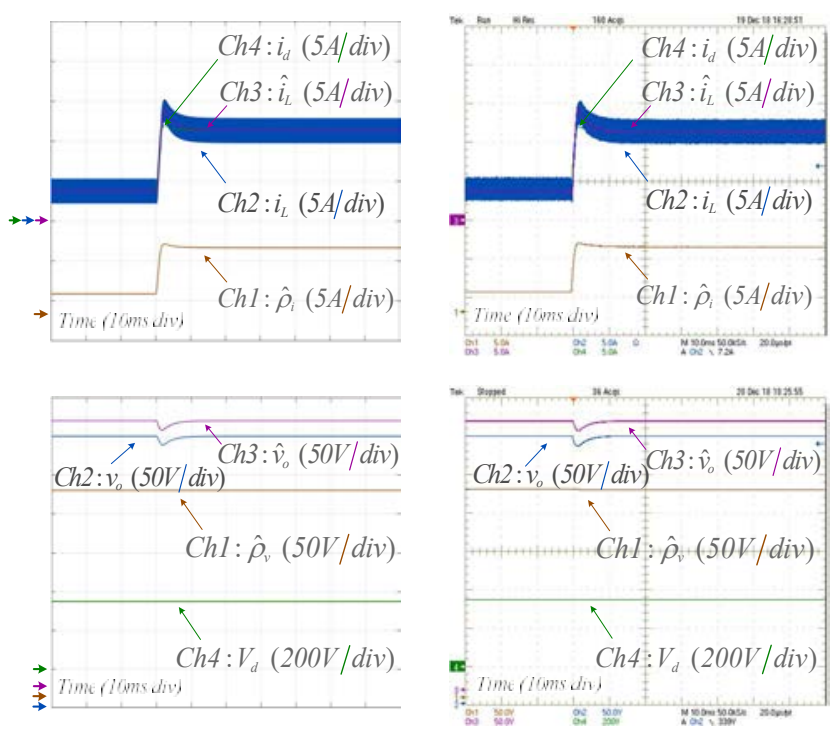

Fig. 9. System response with damping injection when the CPL steps from 1 $\mathrm{kW}$ to $3 \mathrm{~kW}\left(r_{l}=5\right)$, simulation (left) and experimental (right) results.

Besides, the proposed approach is applied to a microgrid level system (different converters interaction) to verify that the system still has good performance without any instability problems. In line with the background described in Section I, a simplified single-bus architecture for aircraft is shown in Fig. 10 [39], [40].

The DC source $(220 \mathrm{~V})$ can be a perfect power source, and it also can be provided by a rectifier from AC-bus or several parallel renewable energies, e.g. FCs and PV. The source converter provides a regulated DC voltage to the $270 \mathrm{~V}$ high voltage DC-bus. Since the DC-bus voltage is not suitable for the load side, the load converters are used to adjust the voltage level. Here, it mainly contains one source converter and three load converters cascaded with their CPL. The DC/DC boost converter with the circuit parameters $\left(L, C\right.$, and $\left.r_{L}\right)$ given in Table II is used for these converters. The first CPL load requires $350 \mathrm{~V}$ input voltage and its power steps from $2 \mathrm{~kW}$ to $3 \mathrm{~kW}$. The second CPL load requires $400 \mathrm{~V}$ input voltage and its power is maintained at $0.8 \mathrm{~kW}$. The third CPL load requires $500 \mathrm{~V}$ input voltage and its power is maintained at $4.5 \mathrm{~kW}$. The proposed $\mathrm{PBC}$ controller and observer is implemented in each $\mathrm{DC} / \mathrm{DC}$ converter.

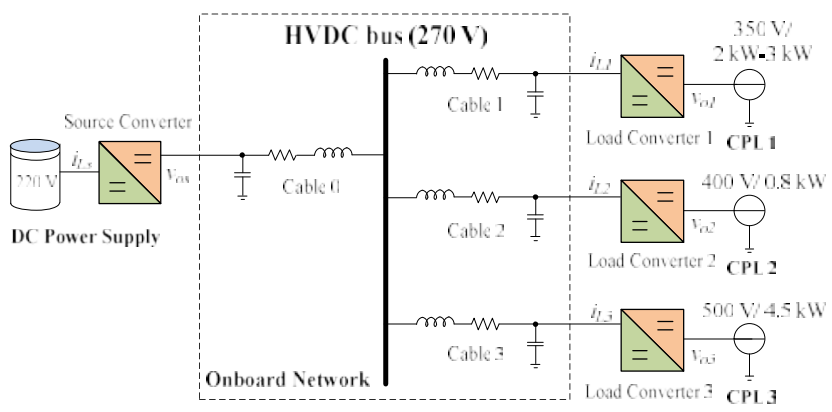

Fig. 10. A simplified single-bus architecture for aircraft. 
The simulation results are shown in Figs. 11-14. The state variable $x=\left[i_{L} v_{o}\right]^{T}$, the estimated value of the state variable $\hat{x}=\left[\hat{\imath}_{L} \hat{v}_{o}\right]^{T}$, and the desired equilibrium point $x_{d}=\left[i_{d} V_{d}\right]^{T}$ are depicted in the same figure to illustrate the effectiveness of the proposed control law. As shown, the good performances of trajectory tracking in output voltage and inductance current are validated. The estimated values converge to the actual ones and exactly track their desired value in all cases. There are no steady-state errors for the state variables, especially the output voltage. Also, the system does not have any instability issues.
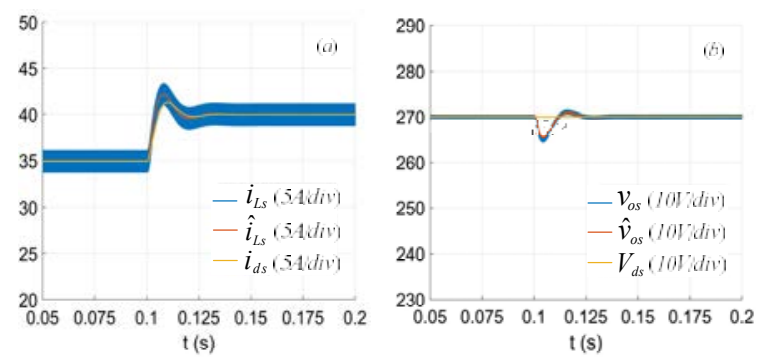

Fig. 11. Simulation results of the source converter. (a) Current response. (b) Voltage response.
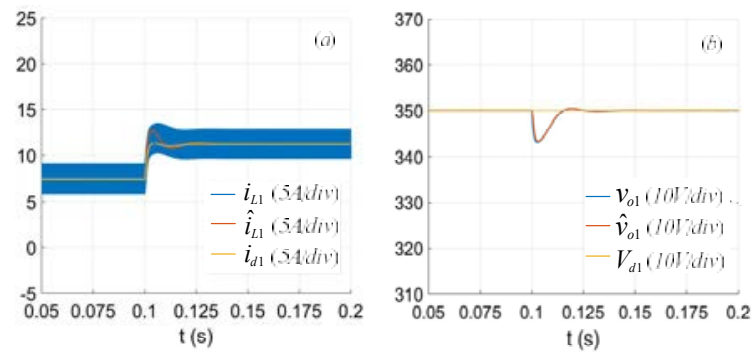

Fig. 12. Simulation results of the load converter 1. (a) Current response. (b) Voltage response.
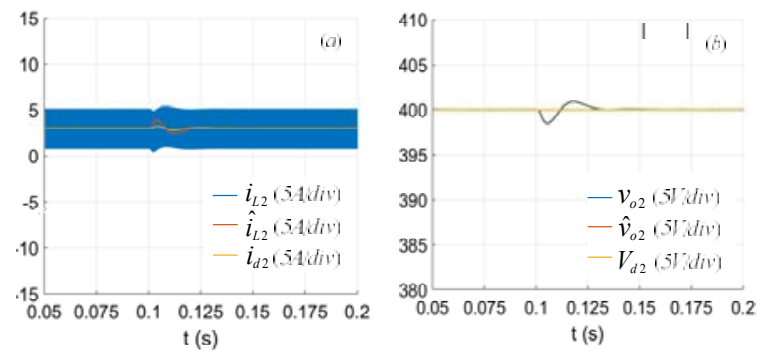

Fig. 13. Simulation results of the load converter 2. (a) Current response. (b) Voltage response.
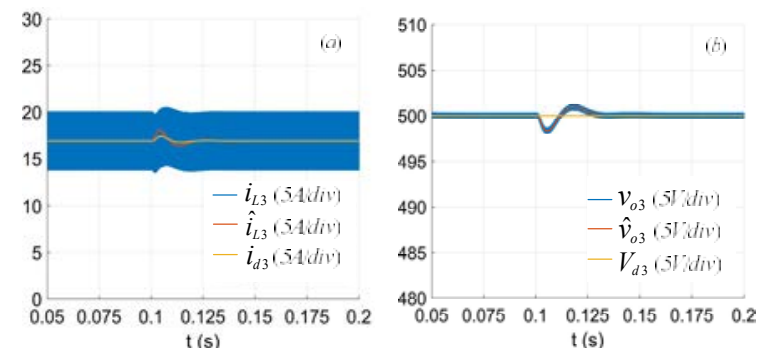

Fig. 14. Simulation results of the load converter 3. (a) Current response. (b) Voltage response.
Moreover, based on the control objectives given in Section I, the comparison with the prior art including all pros and cons is summarized as follows:

As for the conventional IDA-PBC, Objective 1) and Objective 2) can be ensured by the passivity property. However, an output voltage deviation is emerged due to the parameter uncertainties. Moreover, there are four sensors which should be used in the DC/DC boost converter application using the conventional IDA-PBC. Therefore, Objective 3) and Objective 4) cannot be reached by the conventional IDA-PBC.

As for the conventional PID (as well as PI) control with perfectly designed parameters under a specific equilibrium point, Objective 1), Objective 3), and Objective 4) can be ensured. Unfortunately, Objective 2) is hard to achieve. Although there is absolutely no restriction to employ a PID controller to ensure the stability margins and get satisfactory closed-loop performances with a single DC/DC converter. However, when putting this in the big picture of the onboard DC microgrid with its intrinsic dynamic reconfigurations during its mission, the stability analysis of the whole system becomes complex because every single subsystem and every single configuration have to be considered. Therefore, the stability of the whole microgrid system is difficult to guarantee. In particular, the large-signal stability of a microgrid including the PID-controlled DC/DC converter is very complex compared to the case where the proposed PBC-controlled DC/DC converter is employed in the microgrid. Furthermore, if the equilibrium point or the circuit parameters vary, the controller is better to be redesigned to keep its optimal performance. It is about Objective 1) on the robustness of the closed-loop control system. Moreover, from dynamic performances point of view, comparing the proposed approach with the conventional PID controller, with a set of specific circuit parameters and equilibrium point, do not provide a comprehensive result.

As for the proposed approach, Objective 1) and Objective 2) can be guaranteed by the passivity property and by selecting a proper Lyapunov function. As shown in the paper, the proposed PBC with the estimation technique cannot only eliminate the steady-state error on all the state variables but also reduce the countable number of sensors. Therefore, all the objectives can be guaranteed using the proposed controller and observer. The above discussion can be generally summarized in Table III.

TABLE III

General Comparison of the Proposed Control with CONVENTIONAL CONTROL APPROACHES

\begin{tabular}{lccc}
\hline \hline & $\begin{array}{c}\text { Conventional } \\
\text { IDA-PBC }\end{array}$ & $\begin{array}{c}\text { Conventional } \\
\text { PID control }\end{array}$ & $\begin{array}{c}\text { Proposed } \\
\text { control }\end{array}$ \\
\hline Objective 1) & Yes & Yes & Yes \\
Objective 2) & Yes & No & Yes \\
Objective 3) & No & Yes & Yes \\
Objective 4) & No & Yes & Yes \\
\hline \hline
\end{tabular}

\section{RESUlts WITH PARAMETERS UNCERTAINTIES}

The results given in the previous section are based on if the system parameters are completely known, which is not usually 
the case in practice. To evaluate the robustness of the proposed PBC approach for dealing with parameters uncertainties, the errors on the electrical parameters are considered in this section.

For easier comparison with the previous tests, the same experimental scenarios are performed, i.e. the input voltage is $270 \mathrm{~V}$ and output voltage reference $V_{r e f}\left(V_{d}\right)$ is set to $350 \mathrm{~V}$, and the CPL power steps from $1 \mathrm{~kW}$ to $3 \mathrm{~kW}$.

Above all, the simulation and experimental results are conducted with $+50 \%$ errors of its nominal value on $L, C$, and $r_{L}$. Fig. 15 and Fig. 16 show the results for different damping values of $r_{l}$, respectively. As expected, All the estimated values converge towards the actual values, and they track the references well. The system operates without any stability problems and steady-state errors. The overshoot of the current and voltage are almost the same as those with nominal parameters. Only a slight increase is shown in the settling time.
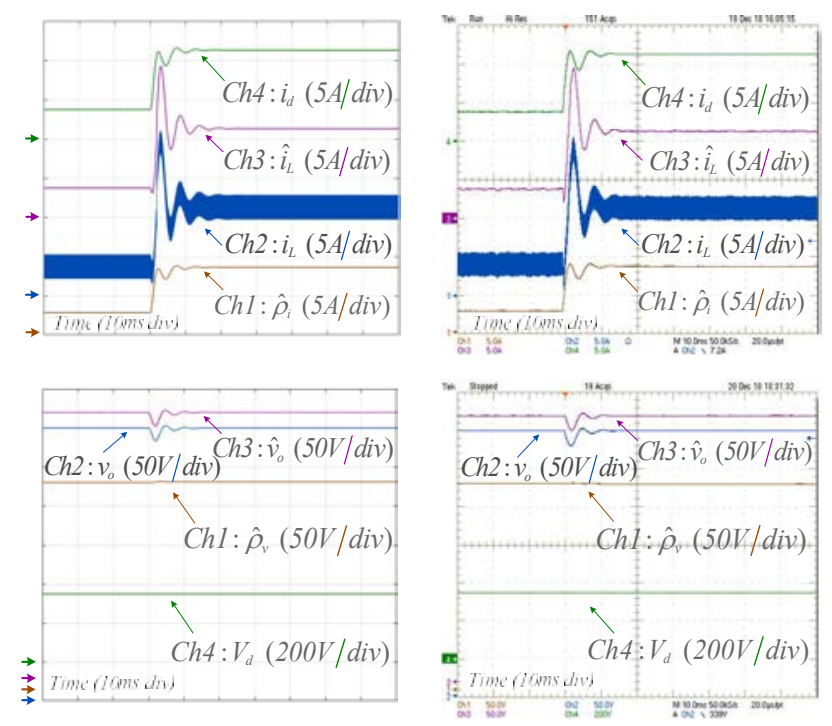

Fig. 15. System response $\left(r_{I}=1\right)$ with $+50 \%$ errors on electrical parameters, simulation (left) and experimental (right) results.
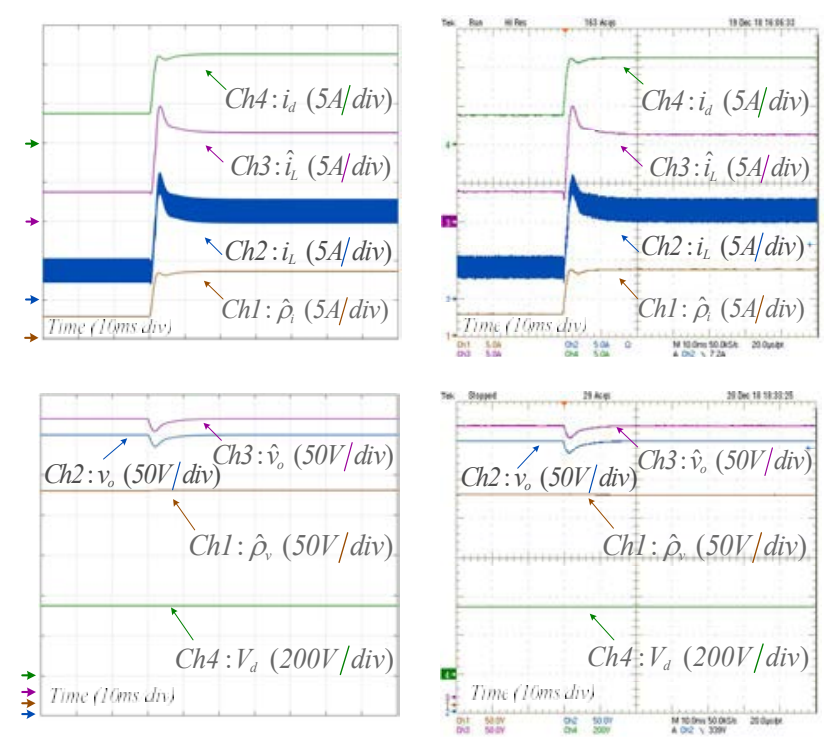

Fig. 16. System response $\left(r_{I}=3\right)$ with $+50 \%$ errors on electrical parameters, simulation (left) and experimental (right) results.
Moreover, parameters errors of $-50 \%$ on $L, C$, and $r_{L}$ are considered in the remaining two tests, i.e. Figs. 17 and 18. The estimation is still converged without any steady-state errors. Emphatically, in the slightly damping case, there is a relatively large peak overshoot current and a long settling time. As the damping value increases, the dynamic performances are improved.

In summary, regarding all the results given above, the system exhibits a good static and dynamic performance. There are no steady-state errors for all the state variables. Also, the system does not have any instability issues. Compared to the conventional IDA-PBC [15], the proposed method can reduce the countable number of sensors by $50 \%$. Therefore, the power density is increased, and the cost is reduced. Consequently, four control objectives mentioned in Section I could be achieved by using the proposed approach.
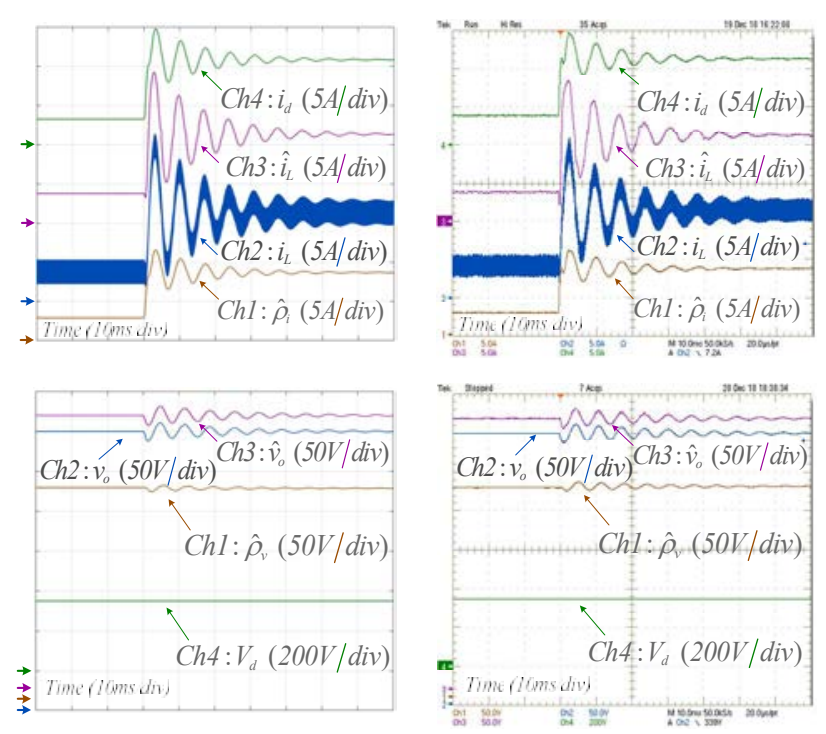

Fig. 17. System response $\left(r_{l}=1\right)$ with $-50 \%$ errors on electrical parameters, simulation (left) and experimental (right) results.
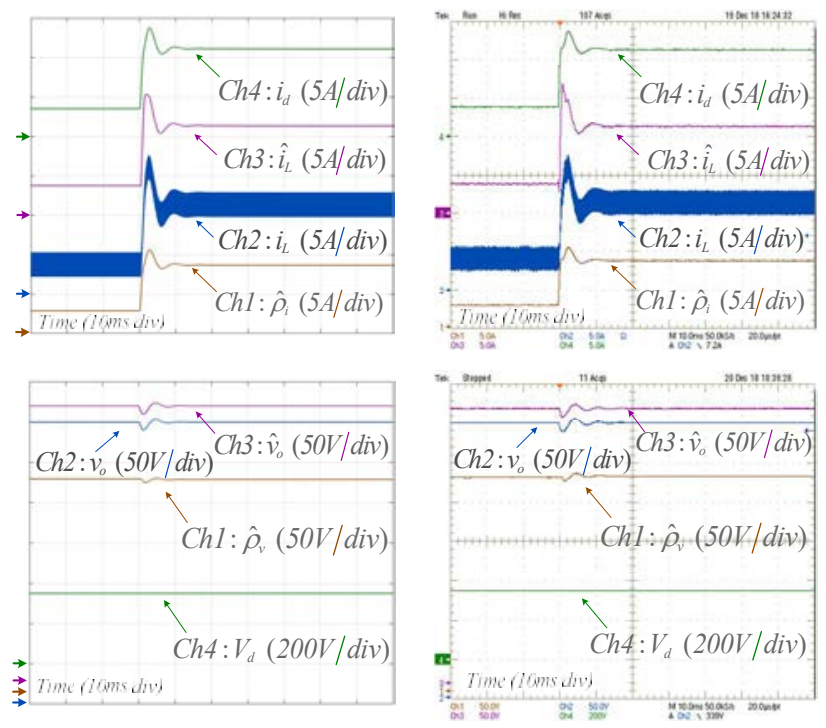

Fig. 18. System response $\left(r_{l}=3\right)$ with $-50 \%$ errors on electrical parameters, simulation (left) and experimental (right) results. 


\section{CONCLUSION}

This paper presents a PBC controller and observer, which are designed simultaneously based on Hamiltonian framework and Lyapunov stability theorem. This permits the system design without separating the controller and observer dynamics. A generalized PBC controller and observer are introduced with the large-signal stability proof. Then, the proposed control strategy is applied as an example to a well-known DC/DC converter.

The conventional IDA-PBC is sensitive to parameter and model accuracy, because this control method is related to the $\mathrm{PCH}$ models, which are based on the precise physical description of the system. In this paper, to eliminate the steadystate errors and to reduce the number of sensors, a nonlinear observer based on the $\mathrm{PCH}$ form is combined with the modified IDA-PBC. All uncertainties in the parameters and model (mainly refer to losses) are taken into account by an equivalent voltage source and an equivalent current source. The steadystate errors are eliminated by using this estimation technique. To reduce the number of sensors, input voltage and output current with the above equivalent sources are estimated online together. Also, thanks to these equivalent sources, non-ideal converters can be modeled under the $\mathrm{PCH}$ framework for PBC design. The exponential stability of the whole system (converter, controller, and observer) is ensured by selecting a proper Lyapunov function candidate. Numerical simulation and experimental verifications are carried out when the converter supplies a CPL. The results show the robustness and effectiveness of the proposed method.

\section{REFERENCES}

[1] V. Madonna, P. Giangrande, and M. Galea, "Electrical power generation in aircraft: review, challenges, and opportunities," IEEE Trans. Transp. Electrific., vol. 4, no. 3, pp. 646-659, Sep. 2018.

[2] S. Faddel, A. A. Saad, T. Youssef, and O. Mohammed, "Decentralized control algorithm for the hybrid energy storage of shipboard power system," IEEE J. Emerg. Sel. Topics Power Electron., vol. 8, no. 1, pp. 720-731, Mar. 2020

[3] Y. Huangfu, et al. "Stability analysis and active stabilization of on-board DC power converter system with input filter," IEEE Trans. Ind. Electron., vol. 65, no. 1, pp. 790-799, Jan. 2018.

[4] S. Boudoudouh and M. Maaroufi, "Renewable energy sources integration and control in railway microgrid," IEEE Trans. on Ind. Applicat., vol. 55, no. 2, pp. 2045-2052, Mar. 2019.

[5] K. M. Muttaqi, M. R. Islam, and D. Sutanto, "Future power distribution grids: integration of renewable energy, energy storage, electric vehicles, superconductor, and magnetic bus," IEEE Trans. Appl. Supercond., vol. 29, no. 2, pp. 1-5, Mar. 2019.

[6] K. Bellache, M. B. Camara, and B. Dakyo, "Transient power control for diesel-generator assistance in electric boat applications using supercapacitors and batteries," IEEE J. Emerg. Sel. Topics Power Electron., vol. 6, no. 1, pp. 416-428, Mar. 2018.

[7] G. Buticchi, S. Bozhko, M. Liserre, P. Wheeler, and K. Al-Haddad, "Onboard microgrids for the more electric aircraft - technology review," IEEE Trans. Ind. Electron., vol. 66, no. 7, pp. 5588-5599, Jul. 2019.

[8] S. Yousefizadeh, J. D. Bendtsen, N. Vafamand, M. H. Khooban, T. Dragicevic, and F. Blaabjerg, "EKF-based predictive stabilization of shipboard dc microgrids with uncertain time-varying load," IEEE $J$. Emerg. Sel. Topics Power Electron., vol. 7, no. 2, pp. 901-909, Jun. 2019.

[9] A. Accetta and M. Pucci, "Energy management system in dc micro-grids of smart ships: main gen-set fuel consumption minimization and fault compensation," IEEE Trans. on Ind. Applicat., vol. 55, no. 3, pp. 30973113, May 2019.

[10] G. Buticchi, L. F. Costa, D. Barater, M. Liserre, and E. D. Amarillo, “A quadruple active bridge converter for the storage integration on the more electric aircraft," IEEE Trans. Power. Electron., vol. 33, no. 9, pp. 81748186, Sept. 2018.

[11] L. Gil-Antonio, B. Saldivar, O. Portillo-Rodriguez, G. Vazquez-Guzman, and S. M. De Oca-Armeaga, "Trajectory Tracking Control for a Boost Converter Based on the Differential Flatness Property," IEEE Access, vol. 7, pp. 63437-63446, 2019.

[12] S. K. Pandey, S. L. Patil, U. M. Chaskar, and S. B. Phadke, "State and Disturbance Observer-Based Integral Sliding Mode Controlled Boost DC-DC Converters," IEEE Trans. Circuits Syst. II, vol. 66, no. 9, pp. 1567-1571, Sep. 2019.

[13] R. Gavagsaz-Ghoachani, et al, "Observer and Lyapunov-based control for switching power converters with LC input filter," IEEE Trans. Power. Electron., vol. 34, no. 7, pp. 7053-7066, July 2019.

[14] L. Cheng, et al, "Model predictive control for dc-dc boost converters with reduced-prediction horizon and constant switching frequency," IEEE Trans. Power. Electron., vol. 33, no. 10, pp. 9064-9075, Oct. 2018.

[15] S. Pang, et al, "Interconnection and damping assignment passivity-based control applied to on-board dc-dc power converter system supplying constant power load," IEEE Trans. on Ind. Applicat., vol. 55, no. 6, pp. 6476-6485, Nov. 2019.

[16] X. Zhang, X. Ruan, and Q. Zhong, "Improving the stability of cascaded $\mathrm{dc} / \mathrm{dc}$ converter systems via shaping the input impedance of the load converter with a parallel or series virtual impedance," IEEE Trans. Ind. Electron., vol. 62, no. 12, pp. 7499-7512, Dec. 2015.

[17] R. Ortega, and E. Garcia-Canseco. "Interconnection and damping assignment passivity-based control: A survey," Eur. J. control, vol. 10, no. 5, pp. 432-450, Dec. 2004.

[18] W. He and R. Ortega, "Design and Implementation of Adaptive Energy Shaping Control for DC-DC Converters With Constant Power Loads," IEEE Trans. Ind. Inf., pp. 1-1, 2019, doi: 10.1109/TII.2019.2953694.

[19] S. Pang, et al, "IDA-passivity-based control for boost converter with lc filter supplying constant power load," in Proc. IEEE Int. Conf. Elect. Syst. Aircraft, Railway, Ship Propuls. Road Vehicles, pp.1-6, Nov. 2018.

[20] H. Khalil Nonlinear systems. 3rd ed. Prentice Hall, 2002.

[21] Y. Gui, B. Wei, M. Li, J. M. Guerrero, and J. C. Vasquez, "Passivitybased coordinated control for islanded AC microgrid," Applied Energy, vol. 229, pp. 551-561, Nov. 2018.

[22] Y. Gu, W. Li, and X. He, "Passivity-based control of de microgrid for self-disciplined stabilization," IEEE Trans. Power Syst., vol. 30, no. 5, pp. 2623-2632, Sep. 2015.

[23] S. Pang, B. Nahid-Mobarakeh, S. Pierfederici, Y. Huangfu, G. Luo, and F. Gao, "Towards stabilization of constant power loads using IDA-PBC for cascaded lc filter dc/dc converters," IEEE J. Emerg. Sel. Topics Power Electron., pp. 1-1, 2019, doi: 10.1109/JESTPE.2019.2945331.

[24] J. Zeng, Z. Zhang, and W. Qiao. "An interconnection and damping assignment passivity-based controller for a dc-de boost converter with a constant power load," IEEE Trans. Ind. Applicat., vol. 50, no. 4, pp. 23142322, July-Aug. 2014.

[25] J. Yang, W. X. Zheng, S. Li, B. Wu, and M. Cheng, "Design of a prediction-accuracy-enhanced continuous-time MPC for disturbed systems via a disturbance observer," IEEE Trans. Ind. Electron., vol. 62, no. 9, pp. 5807-5816, Sept. 2015.

[26] S.-K. Kim, "Output Voltage-tracking controller with performance recovery property for dc/dc boost converters," IEEE Trans. Contr. Syst. Technol., vol. 27, no. 3, pp. 1301-1307, May 2019.

[27] J. Lu, M. Savaghebi, Y. Guan, J. C. Vasquez, A. M. Y. M. Ghias, and J. M. Guerrero, "A reduced-order enhanced state observer control of dc-dc buck converter," IEEE Access, vol. 6, pp. 56184-56191, 2018.

[28] S-S. Huang, Y. Konishi, Z-Z. Yang, and M-J. Hsieh, "Observer-based capacitor current sensorless control applied to a single-phase inverter system with seamless transfer," IEEE Trans. Power. Electron., vol. 34, no. 3, pp. 2819-2828, March 2019

[29] F. Auger, et al. "Industrial applications of the Kalman filter: A review," IEEE Trans. Ind. Electron., vol. 60, no. 12, pp. 5458-5471, Dec. 2013.

[30] A. G. Beccuti, S. Mariethoz, S. Cliquennois, Shu Wang, and M. Morari, "Explicit model predictive control of dc-dc switched-mode power supplies with extended Kalman filtering," IEEE Trans. Ind. Electron., vol. 56, no. 6, pp. 1864-1874, Jun. 2009.

[31] D. Das, S. Madichetty, B. Singh, and S. Mishra, "Luenberger observer based current estimated boost converter for PV maximum power 
extraction - a current sensorless approach," IEEE J. Photovolt., vol. 9, no. 1, pp. 278 - 286, Jan. 2019.

[32] F. M. Oettmeier, J. Neely, S. Pekarek, R. DeCarlo, and K. Uthaichana, "MPC of switching in a boost converter using a hybrid state model with a sliding mode observer," IEEE Trans. Ind. Electron., vol. 56, no. 9, pp. 3453-3466, Jan. 2009.

[33] S. Pang, et al, "IDA-passivity-based control for on-board dc power converter system with constant power load," in Proc. IEEE Ind. Appl. Soc. Annu. Meeting, pp.1-6, Sept. 2018.

[34] H. Renaudineau, J. P. Martin, B. Nahid-Mobarakeh, and S. Pierfederici, "DC-DC converters dynamic modeling with state observer-based parameter estimation," IEEE Trans. Power Electron., vol. 30, no. 6, pp. 3356-3363, June 2015.

[35] R. Gavagsaz-Ghoachani M. Phattanasak, J. P. Martin, B. NahidMobarakeh, and S. Pierfederici, "A Fixed-Frequency Optimization of PWM Current Controller-Modeling and Design of Control Parameters," IEEE Trans. Transport. Electrific., vol. 4, no. 3, pp. 671-683, Sept. 2018.

[36] R. Ortega, A. Schaft, and B. Maschke, "Interconnection and damping assignment passivity-based control of port-controlled Hamiltonian systems," Automatica, vol. 38, no. 4, pp. 585-596, Apr. 2002.

[37] F. Chang, X. Cui, M. Wang, W. Su, and A. Q. Huang, "Large-signal stability criteria in de power grids with distributed-controlled converters and constant power loads," IEEE Trans. Smart Grid, pp. 1-1, 2020, doi: 10.1109/TSG.2020.2998041.

[38] H. Ahmadi and A. Kazemi, "The islanded micro-grid large signal stability analysis based on neuro-fuzzy model," Int Trans Electr Energ Syst, May 2020, doi: 10.1002/2050-7038.12449.

[39] G. Buticchi, S. Bozhko, M. Liserre, P. Wheeler, and K. Al-Haddad, "Onboard microgrids for the more electric aircraft-technology review," IEEE Trans. Ind. Electron., vol. 66, no. 7, pp. 5588-5599, Jul. 2019.

[40] F. Gao, S. Bozhko, A. Costabeber, G. Asher, and P. Wheeler, "Control design and voltage stability analysis of a droop-controlled electrical power system for more electric aircraft," IEEE Trans. Ind. Electron., vol. 64, no. 12, pp. 9271-9281, Dec. 2017. 